\title{
Circulating miR-122 levels in self-recovering hepatitis E patients
}

Bangari Haldipur and Vidya Arankalle*

\begin{abstract}
Background: Hepatitis E (HE) is prevalent in developing countries in both epidemic and sporadic forms and is characterized by high mortality during pregnancy. miR-122, the major hepatic microRNA has been shown to be modulated during liver diseases. Lack of data in HE led to investigations in non-pregnant (NPR) and pregnant (PR) patients.

Results: Self-recovering NPR patients and pregnant women presenting with clinical (PR-acute) or subclinical (PR-SC) $\mathrm{HE}$ and respective healthy controls were studied. Serum samples were tested for miR-122 levels using qRT-PCR. Acute-phase, NPR patients circulated lower miR-122 levels, reducing further during convalescence. In contrast to previous reports, circulating miR-122 levels did not correlate with serum aminotransferase (ALT). In PR-acute patients, miR-122 levels were significantly lower that reflected pregnancy status and not HEV effect. In PR-SC patients, miR-122 levels were lower than the pregnant controls and reduced further when examined one month apart. A pregnant, fulminant HE patient circulated very high miR-122 levels that increased further during convalescence. Correlation analysis of miR-122 and circulating cytokines showed moderate correlation with CCL2 (subclinical, pregnant) and IL-6 (NPR). This first report revealed downregulation of circulating miR-122 levels in self-recovering NPR-acute patients despite liver damage (raised serum ALT) suggestive of alternate mechanism of secretion in blood.

Conclusion: HEV infection during pregnancy led to differential modulation of serum miR-122 levels that correlated with clinical presentation. Utility of miR-122 as a prognostic marker for severe disease during pregnancy needs to be evaluated.
\end{abstract}

Keywords: Hepatitis E virus, miRNA, Pathogenesis, Pregnancy

\section{Background}

Hepatitis E virus (HEV) is the predominant cause of waterborne, epidemic and sporadic acute viral hepatitis among adults from developing countries [1, 2]. Exposure of susceptible individuals to HEV can lead to: (1) subclinical infection (SC), (2) self-limiting clinical hepatitis (acute viral hepatitis (AVH-E)), and (3) Fulminant hepatic failure (FHF-E). Hepatitis E (HE) during pregnancy is characterized by high mortality $(\sim 15-30 \%)$, especially in the third trimester $[3,4]$. However, HEV etiology has been extended to men and non-pregnant women with FHF [5]. Recently, pregnant women from developed countries were shown to develop FHF-E [6]. HEV has been identified as an emerging cause of chronic hepatitis

* Correspondence: varankalle@yahoo.com

Hepatitis Division, National Institute of Virology, Microbial Containment Complex, Pune, India among immunocompromised patients from developed nations ([7], WHO). The differential clinical progression of HEV infection can be attributed to either the host factors or viral factors or both. In India, genotype-1 infects humans while genotype- 4 is restricted to swine population [8].

MicroRNAs (miRNAs) are 21-23 nucleotide small non-coding RNA molecules that post-transcriptionally regulate gene expression by binding to complementary sequences on target messenger RNA transcripts, usually resulting in translational repression or target degradation and gene silencing $[9,10]$. miRNAs have been shown to have diverse functions in physiology; from cell differentiation, proliferation, apoptosis to the endocrine system, haematopoiesis, limb morphogenesis, fat metabolism etc. [9]. A direct role of miRNAs in immune response has been demonstrated [11]. 
As regulatory molecules, miRNAs are involved in the manifestation of various viral diseases in humans [12]. miRNAs are generally tissue specific and cell-associated, however, they have also been found in the extracellular milieu (circulating miRNAs). Lagos-Quintana reported the first discovery of miR-122 in mice in 2002 in an attempt to identify tissue -specific miRNAs [13]. In 2008, Lawrie et al. first reported the presence of miRNAs in serum [14]. Circulating miRNAs are increasingly being recognized as an emerging class of disease biomarkers $[15,16]$. These miRNAs exhibit a consistent expression profile among healthy individuals. miR-122, the most abundant hepatic microRNA, has been evaluated mainly in chronic hepatitis $B$ virus (HBV), hepatitis $C$ virus (HCV) infections and hepatocellular carcinoma (HCC) [17-24].

In view of severe disease and lack of any information on miR-122 in HEV infection, the present study aims to understand association of circulating miR-122 levels with HEV infection. Further, in view of the high mortality during pregnancy, pregnant women presenting with clinical and subclinical HEV infections were also investigated.

\section{Results}

Standardization of qRT-PCR for determination of miR-122 levels

A quantitative PCR standardized for the determination of miR-122 levels could successfully detect 10 copies of miR-122. The standard curve generated for these standards is shown in Fig. 1a and the corresponding amplification plot is presented in Fig. 1b.
miR-122 levels decrease in HEV infected NPR patients

The NPR patients circulated significantly lower miR-122 levels than the healthy NPR controls ( $p<0.0001$, Fig. 2a). All these patients exhibited high serum ALT levels. Thus, discordance between serum ALT and miR-122 levels, both reflecting liver damage was evident. During convalescence, serum ALT levels returned to normal while miR-122 levels continued to be lower, though comparable with acute-phase levels $(p=0.98)$. There was no correlation of circulating miR-122 levels with serum ALT levels (Fig. 2c). ROC analysis discriminated HEV-infected NPR patients from healthy NPR individuals (AUC $=0.912$ $\pm 0.049,95 \%$ confidence interval $(\mathrm{CI})=0.8681$ to 1.018 ) with $96.97 \%$ sensitivity and $100 \%$ specificity (Fig. $2 b$ ).

These unexpected findings led us to examine human HEV genomes for the presence of miR-122 binding sites. First, the ViTa (vita.mbc.nctu.edu.tw/) virus miRNA target database was searched and found that miR-122 target prediction was done for 4 human HEV sequences. Of these, miR-122 binding sites were detected for 2 sequences in the helicase (3932 3956) and ORF2 (6231 6252) regions respectively. Further analysis detected miR-122 binding sites in all the genotype- 1 human HEV genome sequences available in the GenBank database that could be classified into 4 different patterns.

Circulating miR-122, pregnancy and hepatitis E (Fig. 3) Next, pregnant hepatitis E patients were studied. To compensate for pregnancy-induced immunomodulation, miR122 levels during healthy pregnancy were determined (Fig. 3a). Pregnancy was associated with a significant reduction in miR-122 levels $(p<0.0001)$. Comparison of pregnant patients with clinical disease and healthy pregnant controls
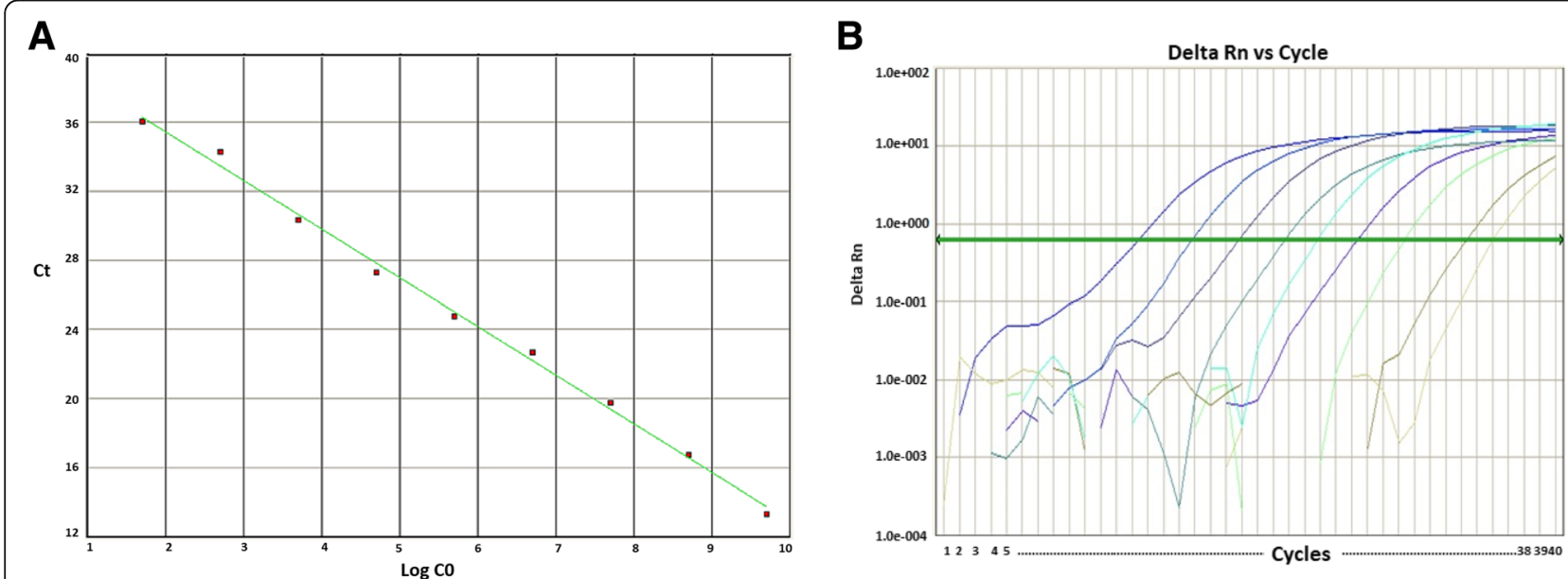

Fig. 1 Standardization of qRT-PCR for determination of miR-122 levels. Circulating miR-122 levels were calculated using a standard curve obtained with synthetic miR-122 oligonucleotide. Synthetic miR-122 was 10-fold serially diluted and qRT-PCR was performed using TaqMan qRT-PCR assays. Standard curve for miR-122 generated is shown in (a) and the corresponding amplification plot is shown in (b) 

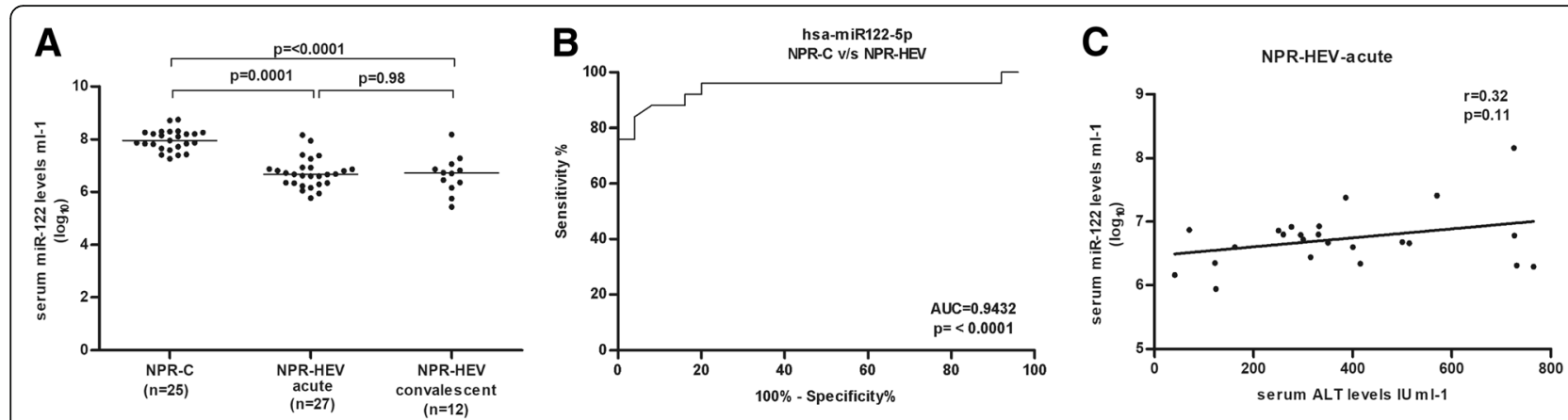

Fig. 2 Circulating miR-122 levels in acute phase, NPR hepatitis E patients. (a) Decreased serum levels of miR-122, in NPR-HEV patients. Scatter plots of serum miR-122 levels in healthy NPR controls (NPR-C, $n=25$ ), NPR HEV infected patients in early (NPR-HEV-acute, $n=27$ ) and convalescent stages (NPR-HEV-conv, $n=12$ ) respectively. NPR-HEV group was subdivided into early and late stage. The line indicates the median value per group. Circulating miR-122 levels are expressed as log 10 of miR-122 copies ml-1 serum. The Mann-Whitney $U$ test was used to determine the statistical significance. $p<0.05$ was considered to be significant. (b) ROC analysis using serum miR-122 for discriminating NPR-HEV patients. ROC curve with corresponding area under curve (AUC) for miR-122 in discriminating NPR-HEV-acute patients from NPR healthy controls. $p<0.05$ was considered to be significant. (c) Correlation of serum miR-122 and ALT levels in NPR-HEV patients. The correlation of serum miR-122 levels with serum ALT levels among acute phase, NPR-HEV patients was determined by Spearman rank correlation coefficient. $r$ indicates the correlation coefficient and $p<0.05$ was considered significant

showed a significant increase in miR-122 levels $(p=0.005$, Fig. 3a). A distinct difference in miR-122 modulation in NPR and PR patients was observed. However, when NPR and PR patients were compared, miR-122 levels were significantly less in the PR patients $(p<0.05)$. Thus, HEV did not reduce miR-122 levels in the PR patients.

Further, circulating miR-122 levels in HEV-infected PR patients presenting with subclinical or self-recovering clinical disease were compared (Fig. 3a). Interestingly, miR-122 levels were significantly lower in the subclinical group when compared to the healthy PR controls $(p=0.03)$ or clinical disease $(p<0.0001)$. We could reexamine $7 / 32$ pregnant women with subclinical infection one month later and found a significant miR-122 downregulation in all $(p=0.0005$, Fig. 3a). No correlation of serum ALT and miR-122 levels was seen (Figs $3 \mathrm{~b}$ and c).

\section{Circulating miR-122 levels in patients with HEV and HBV dual infections}

Figure 4a depicts modulation of miR-122 levels in patients infected with both viruses. Mono-infections were characterized by significantly raised (HBV acute, $p=0.02$ ) or reduced (HEV acute, $p=0.0001$ ) miR-122 levels, as compared to the NPR controls. Accordingly, miR-122 levels in patients with dual infections were significantly lower than HBV alone $(p<0.05)$ and higher than HEV alone $(\mathrm{p}=0.02)$ patients. On the contrary, miR-122 levels were comparable in HBsAg carriers and controls, HEV
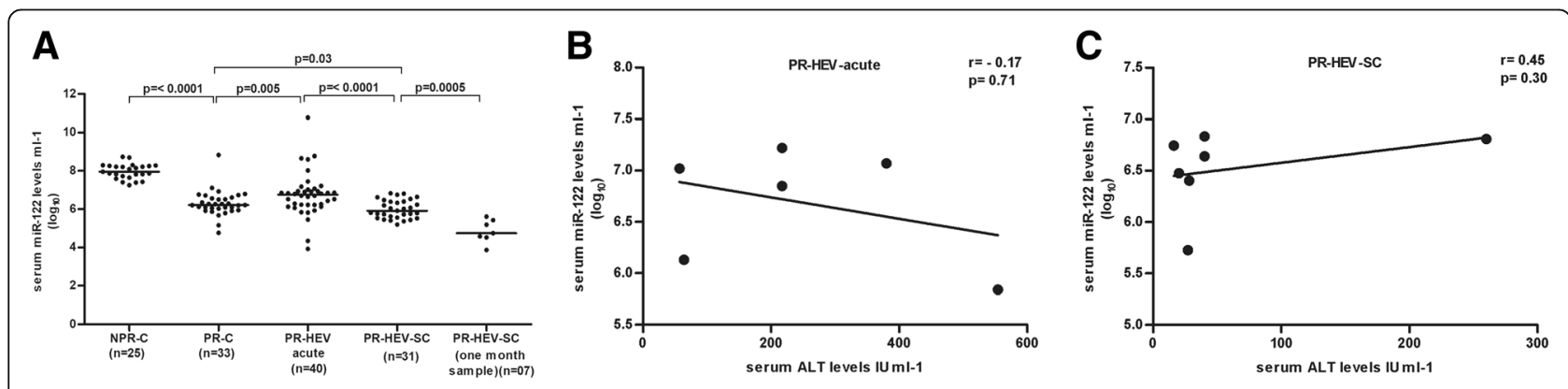

Fig. 3 Circulating miR-122 levels in PR hepatitis E patients presenting with different clinical manifestations. (a) miR-122 levels with respect to clinical manifestations. Scatter plots of serum miR-122 levels in NPR healthy individuals, NPR-C $(n=25)$, healthy PR women, PR-C $(n=33)$, PR acute hepatitis E patients, PR-HEV-acute $(n=40)$, PR women with subclinical HEV infection (PR-HEV-SC, $n=31$ ), PR women bled one month later (PR-HEV-SC-repeat, $n=7$ ). The line indicates the median value per group. Circulating miR-122 levels are expressed as log 10 of miR-122 copies ml1 serum. The Mann-Whitney $U$ test was used to determine the statistical significance. $p<0.05$ was considered to be significant. (b) and (c). Correlation of serum miR-122 and ALT levels in PR-HEV-acute (b) and PR-HEV-SC (c) patients. The correlation of serum miR-122 levels with serum ALT levels was determined by Spearman rank correlation coefficient. $r$ indicates the correlation coefficient and $p<0.05$ was considered significant 

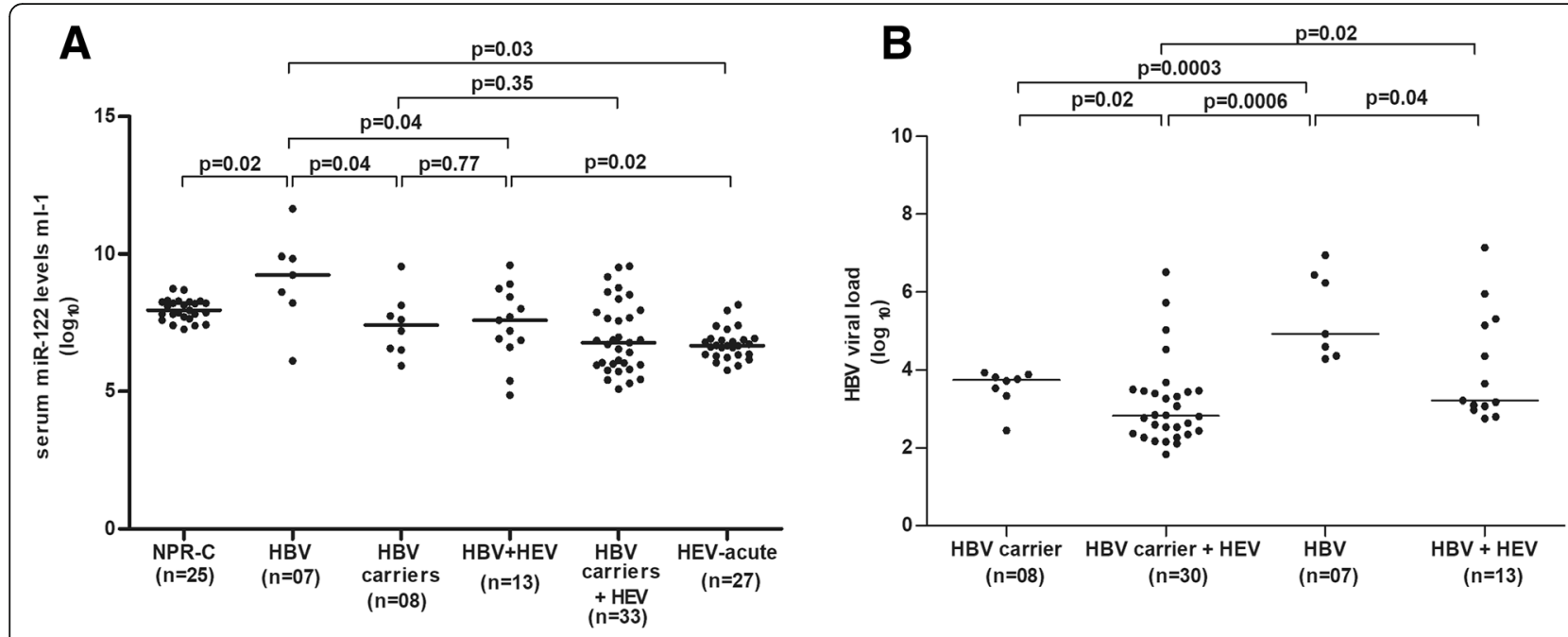

Fig. 4 Serum miR-122 and HBV DNA levels in patients with HBV and HEV dual infection. Scatter plots of (a) serum miR-122 levels and (b) HBV DNA levels in healthy NPR women \& men (NPR, $n=25)$, HBsAg+ antiHBc-lgM+ HEV- (HBV acute, $n=7)$, HBsAg+ antiHBc-lgM- (HBsAg carriers, $n=8)$, hepatitis E patients co-infected with HBV (HBV + HEV, $n=13)$, HBsAg carriers super-infected with HEV (HBsAg carrier $+\mathrm{HEV}, n=33)$. Circulating miR-122 levels and HBV DNA copies were are expressed as log 10 of miR-122 copies ml-1 and HBV viral DNA copies ml-1 serum. The Mann-Whitney $\mathrm{U}$ test was used to determine the statistical significance. $p<0.05$ was considered to be significant

superinfection further had no effect. HBsAg carriers circulated lower miR-122 levels than AVH-B patients suggestive of relationship with active virus replication $(p=0.04)$.

As far as HBV viral load is concerned (Fig. 4b), AVH-B patients exhibited higher circulating HBV DNA levels than the HBsAg carriers $(p=0.003)$ that were predominantly anti-HBe positive. As compared to AVH-B patients, HBV-HEV co-infected patients circulated significantly lower HBV DNA levels $(p=0.04)$. HBsAg carriers with HEV superinfection circulated lower levels of HBV DNA than in the carriers alone $(p=0.02)$.

\section{Correlation with circulating cytokines}

We earlier detected predominant inflammatory response, reduced IFN $\alpha$ and robust chemokine secretion in the NPR patients while the PR patients mounted lower response [25]. The same patients are included here. In view of the observed association of miR-122 levels with IL-6, TNF $\alpha$ and CCL2 [26], correlation of these cytokines with miR-122 levels was evaluated in different groups (Fig. 5). A significant reverse correlation between miR-122 and CCL2 was observed in the PR-HEV-SC group ( $p=0.04 . r=-0.634$, Fig. $5 c)$. Another inflammatory cytokine, showed inverse association of miR-122 with IL-6 in the NPR-HEV-acute patients $(p=0.08, r=-0.62$, Fig. $5 \mathrm{a})$. These results suggest the HEV infection enhances CCL2 and IL- 6 expression by modulating miR-122 levels.

\section{Discussion}

This is the first preliminary study exploring association, if any, of miR-122 with HEV infection. Availability of biopsied liver samples collected for routine diagnosis allowed miR-122 studies in liver/serum samples of chronic hepatitis B and C patients [27-29]. However, HE being predominantly a self-recovering infection, our study is restricted to circulating miRNA levels. In this connection, the observation of serum miR-122 being a surrogate of hepatic miR-122 is noteworthy [30]. We first determined serum miR-122 levels in the NPR-AVH-E patients. Surprisingly, in contrast to the other liver diseases, despite high ALT levels during the acute phase, a significant reduction in miR-122 levels was noted that continued during convalescence with normal ALT levels. Clearly, serum miR-122 was not a function of hepatocyte destruction in these patients. Demonstration of miR-122 binding sites on human HEV genomes indicates that miR-122 binds to HEV genome. One possibility could be requirement of physical binding of miR-122 during $\mathrm{HEV}$ replication leading to reduced serum levels irrespective of liver damage. Our in-vitro experiments did document binding of miR-122 to HEV genome enhancing HEV replication [31].

Next, pregnant women known to be at high risk of developing severe liver disease and mortality were examined. Again, acute-phase, PR-HE patients with raised serum ALT levels circulated lower miR-122 levels when compared to the NPR controls without mutual correlation (Fig. 3a). It therefore appeared that like $\mathrm{HCV}$ [32], miR-122 binding to the viral genome increases 


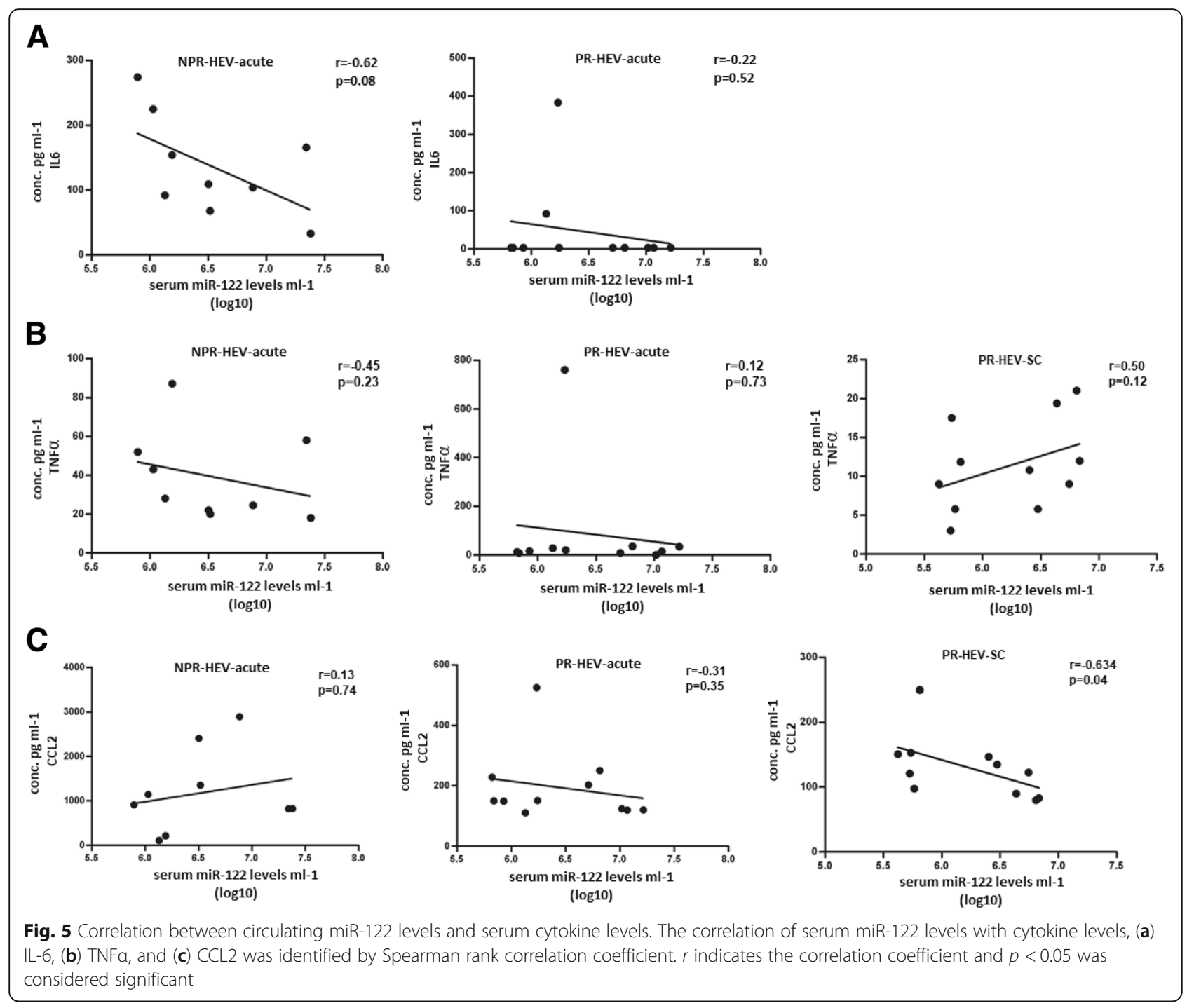

virus replication, though, serum levels were different and use of miR-122 analogues in reducing HEV replication appeared a possibility.

As pregnancy is known for immunomodulation to protect the fetus and the role of miR-122 in pregnancyrelated complications has been reported [33, 34], a further comparison with healthy PR women in the later trimesters was undertaken. Healthy pregnancy was found to be associated with lower miR-122 levels. Notably, pregnancy was shown to significantly reduce more than $50 \%$ of PBMC-miRNAs compared to NPR controls [35]. When healthy pregnant women were taken as controls, a different pattern emerged; serum miR-122 levels varied according to the clinical presentation. The mildest form, subclinical infection, exhibited lower levels which further reduced one month later while the acute-phase patients circulated higher miR-122 levels. Thus, a distinct difference was seen between clinical and subclinical categories during pregnancies, lower levels signifying asymptomatic infection. We would like to mention here a single pregnant FHF patient in the second trimester was investigated during the study period (data not shown). miR-122 levels were significantly higher in this patient (644 fold during acute phase and 42,194 fold during convalescence, as compared to the respective $95 \% \mathrm{CI}$ values (log values, 5.9-6.69; 4.3-5.5) suggestive of very high values in FHF patients. Viraemia was not detected in this patient. Undoubtedly, this observation needs to be confirmed in a larger series of FHF patients. The observed differences in circulating miR-122 levels in acute-phase patients with or without pregnancy suggests that physical binding of the virus cannot be the sole reason for lowering of serum miR-122 levels in the NPR patients. Possibility of alternate mechanism(s) for secretion of miR-122 in the 
bloodstream and influence of pregnancy cannot be ruled out.

In a very recent report based on 13 liver disease-associated fatal cases in a cohort of HIV infected, ART treated individuals, miR-122 was identified as a probable biomarker for liver disease in this population [36]. It would be worthwhile to assess miR-122 as biomarkers for fulminant hepatitis E. A previous study documented 100 fold rise in circulating miR-122 levels in patients with acute liver failure caused by different etiologies [37]. Involvement of miR-122 in addition to miR-21 and miR-221 in spontaneous recovery from FAS-induced ALF is noteworthy [38].

In the same patient population studied earlier, we showed that ALT rise significantly correlated with IgM-anti-HEV titers and the levels of CXCL10, IL-10, sIL2RA and IL-6 levels [25]. In view of the observed association of miR-122 levels with IL-6, TNF $\alpha$ and CCL2 [26], we revaluated correlation of these cytokines with miR-122 levels in different groups. Correlation analysis identified a significant inverse relationship of miR-122 and CCL2 (PR-SC patients) and miR-122 and IL-6 (NPR patients). This is suggestive of role of immune cells in miR-122 modulation in PR-SC group, which requires further studies. Importantly, NPR category showed significant correlation among IL- 6 and ALT [25]. Upregulation of CCL2 in response to decreased miR-122 levels and suppression of miR-122 by IL- 6 has been documented [26].

Enhancement of $\mathrm{HCV}$ propagation through direct interaction of miR-122 with HCV 5' UTR [32] led to intravenous administration of locked nucleic acid (LNA) complementary to miR-122 as a therapy for chimpanzees chronically infected with $\mathrm{HCV}$. This treatment indeed suppressed HCV replication [39]. In view of the in-vitro study reported very recently [31] and the results presented here in HE patients, it would be prudent to explore the utility of miR-122-LNA in the treatment of the disease. Further, if the findings in acute patients are confirmed in the chronic HE patients, LNAs can offer an attractive therapy.

Being an important clinical entity, chronic hepatitis patients dually infected with HBV and HCV have been studied with respect to miR-122 [40]. Our study deals with HBV and HEV dual infections that constitute an important clinical presentation in India, and countries wherein both viruses are endemic [41]. Similar to earlier reports of raised miR-122 levels in CHB patients, we noted higher miR-122 in AVH-B patients. Interestingly, additional infection with HEV causing lowering of miR-122 levels led to balancing between two viruses having opposite effects on serum miR-122 levels (Fig. 4a). Previous studies have shown that during HBV infection, circulating miR-122 levels correlate with liver damage [21] while liver miR-122 levels significantly decrease exhibiting a reverse relationship with inflammation and viral load [21]. Lower HBV DNA levels in both HBsAg carriers and acute HBV patients infected with HEV suggests lowering of HBV replication. This observation needs to be confirmed by longitudinal follow up of the same patients. Being a retrospective, cross-sectional study, lack of serological and clinical follow up of the patients is a limitation. Nonetheless, the interesting observations underscore urgent need for an in-depth study from HEV endemic region and possible use of LNAs in the treatment of hepatitis E.

\section{Conclusion}

Taken together, the results demonstrate that serum miR-122 levels in hepatitis $\mathrm{E}$ do not reflect liver damage suggestive of alternate mechanisms for secretion in blood. The data suggests direct relationship of serum miR-122 levels with disease severity during pregnancy. These findings need to be extended to a larger series of FHF-E patients. Evaluation of this microRNA as a prognostic marker for severe disease during pregnancy seems relevant.

\section{Methods}

\section{Study design and patient samples}

This retrospective study was approved by the "Human Ethics Committee" of National Institute of Virology and was conducted according the guidelines of Indian Council of Medical Research. Since it was a retrospective study, consent of the patient was waived by the ethics committee as left over samples from a previous study were used. The samples were anonymous.

Diagnosis of HE was based on the presence of IgM antibodies to HEV (IgM anti-HEV) by ELISA [42] and only IgM-anti-HEV positives were included. An acute hepatitis $\mathrm{E}$ case was defined as an individual with symptoms suggestive of acute viral hepatitis and a positive IgM-anti-HEV test. A subclinical case was defined as an IgM-anti-HEV positive individual with or without elevated ALT levels, no clinical symptoms at the time of first blood collection and no development of symptoms during 2 months follow-up. These were identified during several epidemics of hepatitis $E$ in villages from the state of Maharashtra, India [25]. A Fulminant hepatic failure case (FHF) is defined as the rapid acute liver injury with rapid deterioration of liver functions and hepatic encephalopathy in a patient without apparent, prior liver disease [43]. Patients with dual HEV \& HBV infections were either co-infected (HEV + HBV, IgM-anti-HEV and IgM-anti-HBc positive) or super-infected (HBsAg+, anti$\mathrm{HBC}-\mathrm{IgM}$ - and IgM-anti-HEV+).

Table 1 describes details of the study population. The study groups included: (A) healthy non-pregnant women \& men (NPR-C, $n=25)$, (B) healthy pregnant women in the 2nd/3rd pregnancy trimesters (PR-C, $n=33$ ), (C) 
Table 1 Characteristics of the study groups

\begin{tabular}{|c|c|c|c|c|c|c|c|c|}
\hline \multirow[t]{2}{*}{ Categories } & \multicolumn{8}{|c|}{ Parameters } \\
\hline & No. & $\begin{array}{l}\text { Age } \\
\text { (mean } \pm \text { SE) }\end{array}$ & $\begin{array}{l}\text { Preg-nancy } \\
\text { (PR) status }\end{array}$ & $\begin{array}{l}\text { Serum } \\
\text { ALT IU/ml } \\
\text { (mean } \pm \text { SE) }\end{array}$ & $\begin{array}{l}\text { Serum } \\
\text { AST IU/ml } \\
\text { (mean } \pm \text { SE) }\end{array}$ & $\begin{array}{l}\text { Bilirubin (mg/dl) } \\
(\text { mean } \pm \mathrm{SE})\end{array}$ & $\begin{array}{l}\text { Serum Protein } \\
\mathrm{gm} / \mathrm{dl} \\
(\mathrm{mean} \pm \mathrm{SE})\end{array}$ & $\begin{array}{l}\text { Serum Albumir } \\
\text { gm/dl } \\
\text { (mean } \pm \text { SE) }\end{array}$ \\
\hline A. NPR-C & 25 & $23 \pm 1.0$ & No & $28.9 \pm 2.7$ & $30.2 \pm 3.1$ & $0.41 \pm 0.04$ & $6.4 \pm 0.1$ & $3.4 \pm 0.1$ \\
\hline B. PR-C & 33 & $22.4 \pm 0.9$ & Yes & $19.8 \pm 0.8$ & $20.1 \pm 0.8$ & $0.19 \pm 0.01$ & $5.3 \pm 0.2$ & $2.1 \pm 0.1$ \\
\hline C. NPR-HEV-acute & 27 & $30.4 \pm 2.5$ & No & $472.9 \pm 63.1$ & $384 \pm 146.9$ & $4.3 \pm 0.9$ & $6.0 \pm 0.1$ & $2.8 \pm 0.1$ \\
\hline D. NPR-HEV-conv & 12 & $30.2 \pm 2.1$ & No & $31 \pm 0.7$ & $89.25 \pm 43.67$ & $2.5 \pm 1.1$ & $6.1 \pm 0.2$ & $2.9 \pm 0.1$ \\
\hline E. PR-HEV-acute & 40 & $23.8 \pm 1.0$ & Yes & $215 \pm 47.7$ & $437 \pm 127.4$ & $4.4 \pm 1.11$ & $4.8 \pm 0.2$ & $1.9 \pm 0.1$ \\
\hline F. PR-HEV-conv & 7 & $23.1 \pm 0.8$ & Yes & $30 \pm 1.7$ & NA & NA & NA & NA \\
\hline G. PR-HEV-SC & 31 & $23 \pm 1.0$ & Yes & $65.1 \pm 8.1$ & $90.56 \pm 52.71$ & $0.5 \pm 0.2$ & $5.6 \pm 0.1$ & $2.3 \pm 0.1$ \\
\hline H. FHF-E & 1 & $23.5 \pm 1.5$ & Yes & 738 & NA & NA & NA & NA \\
\hline I. HBV + HEV & 13 & $20 \pm 1.4$ & No & NA & NA & ND & NA & NA \\
\hline J. HBsAg carriers + HEV & 33 & $23.8 \pm 2.2$ & No & $327 \pm 55.8$ & NA & ND & NA & NA \\
\hline K. HBsAg carriers & 8 & $17.2 \pm 1.6$ & No & $22 \pm 8.5$ & NA & ND & NA & NA \\
\hline L.HBV acute & 7 & $25.4 \pm 1.7$ & No & $437 \pm 63$ & NA & ND & NA & NA \\
\hline
\end{tabular}

The levels of creatinine, urea and globulins were within normal range for all the groups

NA Not applicable, ND Not Done

non-pregnant, AVH-E patients in acute (NPR-HEV-acute, $n=27$ ), and (D) convalescent phase (NPR-HEV-conv, $n=12)$, pregnant women in the later (2nd/3rd) trimesters diagnosed as (E) AVH-E patients (PR-HEV-acute, $n=40$ ) or (F) with subclinical HEV infection (PR-HEV-SC, $n=31$ ), (G) of these, blood samples collected 1 month later were available for 7 pregnant women (PR-HEVSC-repeat, $n=7),(\mathrm{H})$ one pregnant patient with FHF (FHF-E, $n=1$ ), (I) HE patients co-infected with HBV (HBV + HEV, $n=13)$, (J) HBsAg carriers super-infected with HEV (HBsAg carrier+HEV, $n=33$ ), (K) HBsAg+ antiHBc-IgM- (HBsAg carriers, $n=8)$, (L) HBsAg+ antiHBc-IgM+ HEV- (AVH-B /HBV acute, $n=7$ ).

Both the control groups tested negative for IgM/ IgG anti-HEV antibodies [42], $\mathrm{HBsAg}$ and anti-HCV antibodies (ELISA, Abbott laboratories, USA) and exhibited normal values of serum biochemical parameters investigated. Acute NPR and PR hepatitis patients circulated high levels of serum ALT, AST and bilirubin that returned to normal during convalescence. In PR-SC-HEV patients, ALT levels were higher than normal but lower than the acute HE patients. Kidney function tests (urea, creatinine) were normal in all the categories. None of these patients gave $\mathrm{H} / \mathrm{O}$ any chronic disease. In $\mathrm{HBV}$ co-infected patients, only ALT levels were available. The serum biochemical parameters were estimated using an automatic analyser (Dimension RxL Max, Siemens Healthcare, USA).

As the serum samples were stored at $-20^{\circ} \mathrm{C}$, retrospective testing for HEV RNA was not possible. Sample collection, transportation, processing and storage were identical for all the study groups.

\section{RNA isolation}

For all experiments, $400 \mu \mathrm{l}$ of human serum was thawed on ice and lysed with an equal volume of $2 \mathrm{X}$ Denaturing Solution (Ambion, USA). An exogenously added non-homologous miRNA was used as a normalization control owing to the lack of an established housekeeping miRNA as an endogenous control. Synthetic Caenorhabditis elegans miR-39 was spiked-in (25fmol) to each denatured sample prior to RNA extraction (i.e., after combining the plasma sample with Denaturing Solution) as an internal control. RNA was isolated using the mirVana PARIS kit following the manufacturer's protocol for liquid samples (Ambion, USA).

\section{Measurement of serum miR-122 levels}

Briefly, RNA was reverse transcribed using TaqMan miRNA reverse transcription kit and hsa-miR-122-5p and cel-miR-39-5p specific stem-loop primers (Applied BioSystems, USA). Circulating miR-122 levels were quantitated based on a standard curve obtained using synthetic miR-122 oligonucleotide (Integrated DNA Technologies (IDT), Coralville, Lowa) as described below.

\section{Generation of standard curve for absolute quantification of miR-122}

Synthetic single-stranded RNA oligonucleotide (IDT) corresponding to the mature miR-122 sequence (5'-UGGAG UGUGACAAUGGUGUUUG-3', miRBase release v.10.1) was input into the $\mathrm{RT}$ reaction (empirically-derived range: $10^{9}$ copies ml-1 to 10 copies $\mathrm{ml}-1$ ) and standard curve was generated. Absolute copies of miR-122 input into the 
RT reaction were converted to copies of miR-122 ml-1 serum, based on the knowledge that the material input into the RT reaction corresponds to RNA from $\sim 6 \%$ of the total starting volume of serum (i.e., $5 \mu \mathrm{l}$ of the total RNA eluate volume $(80 \mu \mathrm{l}))$.

\section{Normalization of experimental qRT-PCR data using spiked-in C. elegans miRNA as control}

No established endogenous small RNA control exists for normalization of technical variations in sample processing or of potential variation in sample quality. Normalizing by matching the amount of input RNA into the RT reaction is not an appropriate approach because the RNA content of serum can vary considerably and has been suggested to vary with disease states. Hence, a fixed volume of RNA eluate $(5 \mu \mathrm{l})$ from a given volume of starting serum was used, rather than a fixed mass of RNA, as input into RT reaction. Data across the samples was normalized using a median normalization procedure as described earlier by P. Mitchell et al. [44].

\section{Measurement of serum HBV DNA levels}

HBV DNA levels were measured using a real-time PCR assay based on TaqMan chemistry as described earlier [45].

\section{Measurement of cytokine levels}

Plasma cytokines levels were determined using 22-Bio-Plex Protein Array System (Bio-Rad, Herculus, CA, USA) using Milliplex Map Kit according to manufacturer's instructions. For statistical analysis, a value of $0.2 \mathrm{pg} \mathrm{ml}^{-1}$ was used for samples showing undetectable concentrations.

\section{Statistical analysis}

Data were analyzed by non-parametric tests using Wilcoxon test for comparing paired samples, and Mann-Whitney U test for unpaired groups. Receivers operating characteristic (ROC) curves were constructed and the area under curve (AUC) was calculated to evaluate specificity and sensitivity of predictive value or feasibility of using miR-122 as a marker for HE disease severity. Correlation was determined using Spearman's non-parametric analysis. $P<0.05$ was considered statistically significant. All statistical analyses were performed and graphs were generated using GraphPad Prism 7 (GraphPad Software, CA).

\section{Abbreviations}

ALT: Alanine transaminase; AUC: Area under curve; AVH: Acute viral hepatitis; CCL-2: Chemokine (C-C motif) ligand-2; Cl: Confidence interval; ELISA: Enzyme-linked immunosorbent assay; FHF: Fulminant hepatic failure; HBsAg: Hepatitis B surface antigen; HBV: Hepatitis B virus; HCV: Hepatitis C virus; HE: Hepatitis E; HEV: Hepatitis E virus; IL-6: Interleukin-6; miR122: microRNA-122; miRNA: microRNA; NPR: Non-pregnant; PBMC: Peripheral blood mononucleolar cells; PR: Pregnant; SC: Subclinical; TNF-a: Tumor necrosis factor-a; WHO: World health organization

\section{Acknowledgements}

We gratefully acknowledge financial support provided by ICMR. We also thank Director, for all the support provided during this study. Special thanks to Mr. Shirish Vaidya, Satish Ranawade, Prakash Jawalkar, for technical help. We acknowledge the timely help provided by Dashrath Kalluri for locating the stored samples. In addition, Bangari Haldipur also acknowledges UGC for providing the Senior Research Fellowship. We thank Dr. Shubham

Shrivastava for the constructive evaluation of the manuscript.

\section{Funding}

Indian Council of Medical Research, Government of India

Availability of data and materials

All data generated or analysed during this study are included in this published article.

\section{Authors' contributions}

VAA conceived the idea. BH planned and performed the experiments. Both the authors analyzed and interpreted the patient data. Both authors read and approved the final manuscript.

\section{Ethics approval and consent to participate}

This retrospective study was approved by the "Human Ethics Committee" of National Institute of Virology and was conducted according the guidelines of Indian Council of Medical Research. Since it was a retrospective study, consent of the patient was waived by the ethics committee as left over samples from a previous study were used. The samples were anonymous.

Consent for publication

Not applicable.

Competing interests

All authors declare that they have no competing interests.

\section{Publisher's Note}

Springer Nature remains neutral with regard to jurisdictional claims in published maps and institutional affiliations.

Received: 9 June 2018 Accepted: 2 January 2019

Published online: 14 February 2019

\section{References}

1. Arankalle VA, Chobe LP, Jha J, Chadha MS, Banerjee K, Favorov MO, et al. Aetiology of acute sporadic non-a, non-B viral hepatitis in India. J Med Virol. 1993:40(2):121-5.

2. Dalton HR, Hunter JG, Bendall RP, Hepatitis E. Curr Opin Infect Dis. 2013; 26(5):1.

3. Chandra V, Taneja S, Kalia M, Jameel S. Molecular biology and pathogenesis of hepatitis E virus. J Biosci. 2008;33(4):451-64.

4. Khuroo MS, Teli MR, Skidmore S, Sofi MA, Khuroo MI. Incidence and severity of viral hepatitis in pregnancy. Am J Med. 1981;70(2):252-5.

5. Arankalle $\mathrm{V}$, AFavorov $\mathrm{MO}$, Jha J, Favorov $\mathrm{MO}$, Chaudhari A, Fields $\mathrm{HA}$, Banerjee K. Contribution of HEV and HCV in causing fulminant non-a, non-B hepatitis in western India. J Viral Hepat. 1995:2(4):189-93.

6. Lachish T, Erez O, Daudi N, Shouval D, Schwartz E. Acute hepatitis E virus in pregnant women in Israel and in other industrialized countries. J Clin Virol. 2015;73:20-4.

7. Haagsma EB, van den Berg AP, Porte RJ, Benne CA, Vennema H, Reimerink $J \mathrm{HJ}$, et al. Chronic hepatitis $\mathrm{E}$ virus infection in liver transplant recipients. Liver Transpl. 2008;14(4):547-53.

8. Arankalle VA, Chobe LP, Joshi MV, Chadha MS, Kundu B, Walimbe AM Human and swine hepatitis $E$ viruses from Western India belong to different genotypes. J Hepatol. 2002;36(3):417-25.

9. Girard M, Jacquemin E, Munnich A, Lyonnet S, Henrion-Caude A. miR122, a paradigm for the role of microRNAs in the liver. J Hepatol. 2008; 48(4):648-56

10. Bartel DP. MicroRNAs: target recognition and regulatory functions. Cell. 2009;136(2):215-33.

11. Gantier MP, Sadler AJ, Williams BR. Fine-tuning of the innate immune response by microRNAs. Immunol Cell Biol. 2007;85:458-62. 
12. Bogerd HP, Skalsky RL, Kennedy EM, Furuse Y, Whisnant AW, Flores O, et al. Replication of many human viruses is refractory to inhibition by endogenous cellular microRNAs. J Virol. 2014;88(14):8065-76.

13. Lagos-Quintana M, Rauhut R, Yalcin A, Meyer J, Lendeckel W, Tuschl T. Identification of tissue-specific microRNAs from mouse. Curr Biol. 2002;12(9):735-9.

14. Lawrie $\mathrm{CH}$, Gal S, Dunlop HM, Pushkaran B, Liggins AP, Pulford K, et al. Detection of elevated levels of tumour-associated microRNAs in serum of patients with diffuse large B-cell lymphoma. Br J Haematol. 2008; 141(5):672-5.

15. Wang K, Zhang S, Marzolf B, Troisch P, Brightman A, Hu Z, et al. Circulating microRNAs, potential biomarkers for drug-induced liver injury. Proc Natl Acad Sci. 2009;106(11):4402-7.

16. Zhang Y, Jia Y, Zheng R, Guo Y, Wang Y, Guo H, et al. Plasma microRNA-122 as a biomarker for viral-, alcohol-, and chemical-related hepatic diseases. Clin Chem. 2010;56(12):1830-8.

17. Bihrer V, Friedrich-Rust M, Kronenberger B, Forestier N, Haupenthal J, Shi Y, et al. Serum miR-122 as a biomarker of Necroinflammation in patients with chronic Hepatitis C virus infection. Am J Gastroenterol. 2011;106(9):1663-9.

18. Xing TJ, Jiang DF, Huang JX, Xu ZL. Expression and clinical significance of miR-122 and miR-29 in hepatitis B virus-related liver disease. Genet Mol Res. 2014;13(3):7912-8.

19. Waidmann O, Bihrer V, Pleli T, Farnik H, Berger A, Zeuzem S, et al. Serum microRNA-122 levels in different groups of patients with chronic hepatitis $B$ virus infection. J Viral Hepat. 2012;19(1365-2893):e58-65.

20. Wang S, Qiu L, Yan X, Jin W, Wang Y, Chen L, et al. Loss of microRNA 122 expression in patients with hepatitis $B$ enhances hepatitis $B$ virus replication through cyclin G 1-modulated P53 activity. Hepatology. 2012;55(3):730-41.

21. Jiao X, Fan Z, Chen H, He P, Li Y, Zhang Q, et al. Serum and exosomal miR122 and miR-199a as a biomarker to predict therapeutic efficacy of hepatitis C patients. J Med Virol. 2017;89(9):1597-1605.

22. Oliveira KG, Malta FM, Nastri ACSS, Widman A, Faria PL, Santana RAF, et al. Increased hepatic expression of miRNA-122 in patients infected with HCV genotype 3. Med Microbiol Immunol. 2016;205(2):111-7.

23. Coulouarn C, Factor VM, Andersen JB, Durkin ME, Thorgeirsson SS. Loss of miR-122 expression in liver cancer correlates with suppression of the hepatic phenotype and gain of metastatic properties. Oncogene. 2009; 28(40):3526-36.

24. Qiao D-D, Yang J, Lei X-F, Mi G-L, Li S-L, Li K, et al. Expression of microRNA122 and microRNA-22 in HBV-related liver cancer and the correlation with clinical features. Eur Rev Med Pharmacol Sci. 2017;21(4):742-7.

25. Ramdasi AY, Arya RP, Arankalle VA. Effect of pregnancy on anti-HEV antibody titres, plasma cytokines and the corresponding gene expression levels in the PBMCs of patients presenting with self-recovering clinical and subclinical hepatitis E, Jhaveri R, editor. PLoS One. 2014;9(8):e103257.

26. Li C, Deng M, Hu J, Li X, Chen L, Ju Y, et al. Chronic inflammation contributes to the development of hepatocellular carcinoma by decreasing miR-122 levels. Oncotarget. 2016;7(13):17021-34.

27. Morita K, Taketomi A, Shirabe K, Umeda K, Kayashima H, Ninomiya M, et al. Clinical significance and potential of hepatic microRNA-122 expression in hepatitis C. Liver Int. 2011;31(4):474-84.

28. Butt AM, Raja AJ, Siddique S, Khan JS, Shahid M, G-U-NU T, et al. Parallel expression profiling of hepatic and serum microRNA-122 associated with clinical features and treatment responses in chronic hepatitis $C$ patients. Sci Rep. 2016;6:21510.

29. Trebicka J, Anadol E, Elfimova N, Strack I, Roggendorf M, Viazov S, et al. Hepatic and serum levels of miR-122 after chronic HCV-induced fibrosis. J Hepatol. 2013;58(2):234-9.

30. Hegde UC. Immunomodulation of the mother during pregnancy. Med Hypotheses. 1991;35(2):159-64

31. Haldipur B, Bhukya PL, Arankalle V, Lole K. Positive regulation of hepatitis E virus replication by microRNA-122. J Virol. 2018;92(11).

32. Jopling CL, Yi M, Lancaster AM, Lemon SM, Sarnow P. Modulation of Hepatitis C virus RNA abundance by a liver-specific microRNA. Science. 2005;1:1577-81.

33. Carreras-Badosa G, Bonmatí A, Ortega F-J, Mercader J-M, Guindo-Martínez $M$, Torrents $D$, et al. Altered circulating miRNA expression profile in Pregestational and gestational obesity. J Clin Endocrinol Metab. 2015; 100(11):E1446-56.

34. Lasabová Z, Vazan M, Zibolenova J, Svecova I, Vážan M, Zibolenová J, et al. Overexpression of miR-21 and miR-122 in preeclamptic placentas. Neuroendocr Lett Neuroendocrinol Lett. 2015;36(7):695-9.
35. Trehanpati N, Sehgal R, Patra S, Vyas A, Vasudevan M, Khosla R, et al. MiRNA signatures can predict acute liver failure in hepatitis $\mathrm{E}$ infected pregnant females. Heliyon. 2016;3:e00287.

36. Murray DD, Suzuki K, Law M, Trebicka J, Neuhaus Nordwall J, Johnson M, et al. Circulating miR-122 and miR-200a as biomarkers for fatal liver disease in ART-treated, HIV-1-infected individuals. Sci Rep. 2017;7(1):10934.

37. Dubin PH, Yuan H, Devine RK, Hynan LS, Jain MK, Lee WM, et al. Micro-RNA122 levels in acute liver failure and chronic hepatitis C. J Med Virol. 2014; 86(9):1507-14

38. Sharma AD, Narain N, Händel E-M, Iken M, Singhal N, Cathomen T, et al. MicroRNA-221 regulates FAS-induced fulminant liver failure. Hepatology. 2011;53(5):1651-61.

39. Lanford RE, Hildebrandt-Eriksen ES, Petri A, Persson R, Lindow M, Munk ME, et al. Therapeutic silencing of microRNA-122 in primates with chronic hepatitis C virus infection. Science. 2010;327(5962):198-201.

40. Cheng H-R, Kao J-H, Wu H-L, Tseng T-C, Liu C-H, Yang H-C, et al. Clinical significance of circulating miR-122 in patients with dual chronic hepatitis B and C virus infection. Hepatol Int. 2015;9(1):35-42.

41. Cheng S, Mai L, Zhu F, Pan X, Sun H, Cao H, et al. Influence of chronic HBV infection on superimposed acute hepatitis E. World J Gastroenterol. 2013; 19(35):5904-9.

42. Arankalle VA, Lole KS, Deshmukh TM, Chobe LP, Gandhe SS. Evaluation of human (genotype 1) and swine (genotype 4)-ORF2-based ELISAs for antiHEV IgM and IgG detection in an endemic country and search for type 4 human HEV infections. J Viral Hepat. 2007;14(6):435-45.

43. Bin YB, Arshad R, Khurhsid S, Masood J, Nazir F, Tahira M. Fulminant hepatic failure (FHF) due to acute hepatitis C. Pakistan J Med Sci. 1969;31(4):1009-11.

44. Mitchell PS, Parkin RK, Kroh EM, Fritz BR, Wyman SK, Pogosova-Agadjanyan EL, et al. Circulating microRNAs as stable blood-based markers for cancer detection. Proc Natl Acad Sci. 2008;105(30):10513-8.

45. Lole KS, Arankalle VA. Quantitation of hepatitis B virus DNA by real-time PCR using internal amplification control and dual TaqMan MGB probes. J Virol Methods. 2006:135(1):83-90.

\section{Ready to submit your research? Choose BMC and benefit from:}

- fast, convenient online submission

- thorough peer review by experienced researchers in your field

- rapid publication on acceptance

- support for research data, including large and complex data types

- gold Open Access which fosters wider collaboration and increased citations

- maximum visibility for your research: over $100 \mathrm{M}$ website views per year

At BMC, research is always in progress.

Learn more biomedcentral.com/submissions 